DOE/ER/60304-10

\title{
SENSITIVITY OF CLIMATE MODELS: COMPARISON OF SIMULATED AND OBSERVED PATTERNS FOR PAST CLIMATES
}

\author{
Progress Report \\ for Period February 1, 1994-January 31, 1995 \\ J. Kutzbach, R.J. Oglesby \\ W.L. Prell, Thompson Webb, III
}

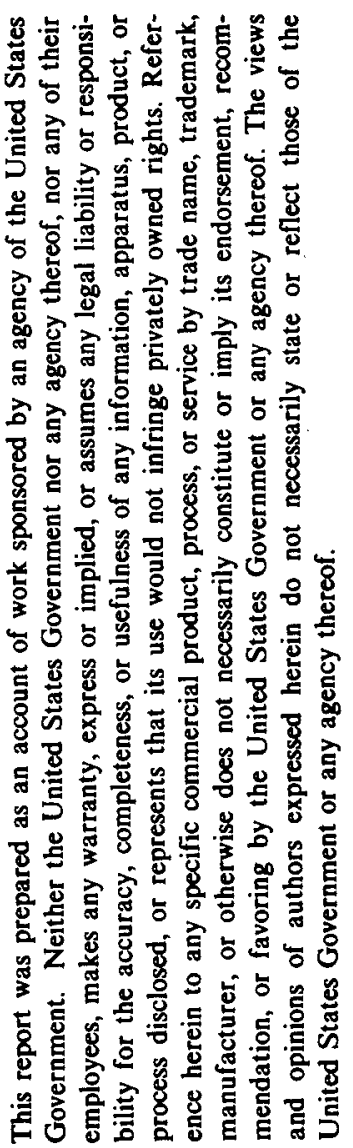

\author{
Brown University \\ Providence, Rhode Island 02912
}

October 1994

Prepared for

THE U.S. DEPARTMENT OF ENERGY

AGREEMENT NO. DE-FG02-85ER60304 


\section{DISCLAIMER}

\section{Portions of this document may be illegible in electronic image products. Images are produced from the best available original document.}




\section{PROGRESS REPORT}

1994

\section{SENSITIVITY OF CLIMATE MODELS: COMPARISON OF SIMULATED AND OBSERVED PATTERNS FOR PAST CLIMATES}

\section{INTRODUCTION}

General circulation models of the atmosphere and oceans are key to the predicition of the potential climate changes that may be induced by increased concentrations of greenhouse gases. Confidence in the predictions of these models can be gained by testing of these models in their ability to simulate past climates. Estimates of global mean temperature change show that the magnitude of warming since the last glacial maximum 21,000 calendar years ago match the magnitude of warming currently being predicted for the doubling of carbon dioxide in the atmosphere. Simulations of the climatic changes for the past 21,000 years as well as for warmer-than-present climates at 6000 and 125,000 years ago provide an excellent opportunity to test the models that are being used in global climate change research. Recognition of this opportunity has been central to our DOE research for the past decade and is now central to PMIP (Paleoclimate Modeling Intercomparison Project) to which our research is contributing.

During the past year, we have used paleoclimatic data to test the accuracy of the NCAR CCM1 (National Center for Atmospheric Research, Community Climate Model, Version 1), after changing its boundary conditions to those appropriate for past climates. We have also completed a series of sensitivity tests to evaluate the model response to changes in selected boundary conditions. These experiments add to our earlier series of experiments with the NCAR CCM0 (Wright et al., 1993) and also include runs of 6000 and 21,000 years ago for use in PMIP. For testing these new results, we have added to the regional and near-global data sets that we assembled for testing the NCAR CCM0 (COHMAP, 1988). We have also continued to improve the methods that permit quantitative comparisons between the data and model results (Webb et al., 1993). Our comparions have shown some improved climate simulations by CCM1 and some greater inaccuracies.

Our research continues to show that the comparison of model results with the data is an evolutionary process because of continuous improvements to the models, data, and methods for comparison. Adding a seasonal cycle and interactive components for soil moisture and sea-surface temperatures to CCM1 has provided a several new opportunities for testing the model performance both with simulation experiments and with sensitivity tests. Many of these results were discussed at the COHMAP workshop in Madison in late June, 1994.

\section{GENERAL RESEARCH ACCOMPLISHMENTS DURING 1994}

The COHMAP book Global Climates Since the Last Glacial Maximum (Wright et al., 1993) describing the climate-model simulations, regional and global data sets, and the comparisons between the data and model results was finally released in early 1994. The book was featured at American Quaternary Association Meeting in Minneapolis, $M N$ in June, 1994. Other key accomplishments included 1) completion of a new set of COHMAP baseline experiments for $21,000,16,000,14,000,11,000$, and 6000 years ago, 2) completion of runs by CCM1 for 21,000 and 6000 years ago for PMIP (Paleoclimate Modeling Intercomparison Project), 3) completion of a new series of sensitivity experiments, 4) acceptance for publication of a sensitivity study of orbital forcing (Felzer 
et al., 1995), 5) publication of the initial results of sensitivity studies on the impact of ice sheets with CCM1 (Felzer et al., 1994), 6. data/model comparisons of modern SST data with the Control simulation of the CCM1 mixed layer ocean, 7. organization of an international group to compile a global paleovegetation data set (Prentice and Webb, 1994), 8. completion of a study of the response of CCM1 to pre-industrial levels of carbon dioxide in contrast to modern levels (Marshall et al., 1994), 9. addition of an improved snow hydrology scheme to CCM1 (Marshall and Oglesby, 1994), 10. publication of a sensitivity test for vegetation on climate (Foley et al., 1994), and 11. assessment of the sensitivity of snow cover and sea-ice cover to orbital extremes (Gallimore and Kutzbach, 1994).

\section{COHMAP BASELINE EXPERIMENTS}

We ran a new set of simulations for $21,000,16,000,14,000,11,000$, and 6000 years ago using CCM1. CCM1 simulates the full seasonal cycle, has interactive soil moisture and snow cover, and is coupled to a $50 \mathrm{~m}$ mixed-layer ocean with interactive ocean temperature and sea-ice. These experiments also incorporated the new estimates of ice sheet height (ICE-3G) developed over the past several years by Peltier and others, and the latest estimates of $\mathrm{CO}_{2}$ level. These new results formed an important focus for the COHMAP meeting that was held in Madison during the period 24-28 June 1994. Some 83 individuals from 38 institutions participated in the meeting. Several publications are planned based upon the results.

The simulated climates from CCM1 agree in many respects with our previous results with CCMO (Wright et al., 1993); however, there are also significant differences. At 21,000 years ago there is a split jet stream over North America (as simulated previously), however, the split is not as large owing to the reduced height of the ice sheet. Temperatures over land are generally lower than in our previous experiments. This difference is in part caused by the lowered level of $\mathrm{CO}_{2}$. Ocean mixed-layer temperatures are 2-4 $\mathrm{C}$ lower than present and are also lower than those estimated by CLIMAP from plantonic data. This change is also related to the lowered level of $\mathrm{CO}_{2}$ and the simulations by the mixed-layer ocean.

At $6000 y r$ BP the amplified seasonal cycle of solar radiation (caused by orbital changes) causes enhanced northern summer monsoons in the tropics. These changes now include the effects of soil moisture. In general, we find that the new simulations of precipitation-minus-evaporation agree more closely with lake level data in Africa and Eurasia from $6000 \mathrm{yr}$ BP than did our previous results with CCMO (Harrison et al., in prep.), and the simulated moisture balance for central North America, although not less than present like the data show, is not greater than present as CCMO simulated (Webb et al., 1993)

At some times and places, the new simulations give distinctly worse results than CCM0. For example, from 16,000 to 11,000 yr BP over eastern North America summer conditions are much warmer than inferred from pollen data. In this case, it appears that the interactive soil moisture parameterization produces excessive drying of the soil in spring leading to unrealistically higher temperatures in summer in response to the enhanced solar radiation. Pinpointing such model discrepencies is a key task of our DOE research. 


\section{Data/Model Comparisons}

- Developments with Model Output

We are working with G. Bonan (NCAR) using the CCM2 to simulate $6000 \mathrm{yr}$ BP climate. This is our first experiment with this new high resolution CCM. The experiment is underway, and in anticipation we have revised our model output processing routines to deal with the larger data sets and to facilitate the comparison of model results with the data.

We have developed a new interactive data acquisition system (CCR-menu) for helping collaborators access our model results. We' have also turned over our COHMAP results from CCMO to the Paleoclimate Data Center at NGDC in Boulder, where they are accessible to the national and international paleoclimate community (Kutzbach and Behling, 1994).

- Terrestrial Data.

Many comparisons were made between terrestrial data and the new CCM1 results for 21,000 years ago to present at the COHMAP Meeting in Madison in June, 1994. Pollen and lake-level data provided the prime sources of information, and many of these data are documented in the recently published COHMAP book (Wright et al., 1993). As mentioned above, the lake-level data yielded generally favorable comparisons for Eurasia and Africa with the P-E simulations from the model. Working groups for Europe, Australasia, North America, and South America also reported on aggreements between the data and the model results. Articles are now being prepared to descibe these results and will appear in an issue of Quaternary Science Reviews. The issue will include articles that describe the model results, key sensitivity experiments, and data/model comparisons at global and regional scales.

In eastern North America, detailed comparisons with climate estimates inferred from the pollen data showed a good match surface temperatures in the southeastern United States at 21,000 years ago. As noted above, CCM1 with computed SST's and lower values of $\mathrm{CO} 2$ gave lower estimates of temperature in this region than did CCMO. The warmer-than-inferred southeastern temperatures by CCM0 for 21,000 years ago were one of the key discrepencies noted by Webb et al. 1993 in the COHMAP book. For 16,000 to 11,000 year ago, CCM1 gives consistently warmer July temperatures than either CCMO simulated or are inferred from the pollen data. As explained above, this discrepency probably arises from diffeciencies in the single-bucket model in the soilmosture paramerization in CCM1.

- Marine Data.

Due to the increasingly important role of SST in interpreting global climate changes (see workshop report), we have focused our efforts on evaluating the ability of CCM1 to simulate modern and past SSTs. CLIMAP estimates of SST at the LGM (1976, $1981,1984)$ have shown large SST decreases in the high and temperate latitudes but only small SST changes in the tropics. Our data-model SST comparisons have initially focused on the ability of the CCM-1 mixed layer ocean to calculate modern SST and have used the Global Oecean S Surface Temperature Atlas (GOSTA) (Bottomly et al., 1990)] data as our modern control climatology. GOSTA is a 30 year (1950-1981) mean monthly climatology of sea surface temperatures. 
- CCM-1 computed SST

Because CCM1 uses a mixed-layer ocean that is only thermodynamic and incorporates a globally averaged zonal approach to adjusting imbalances in the ocean heat transport (Q flux), CCM-1 cannot be expected to calculate the correct SST in areas where active dynamics override the simple thermodynamic heat flux. Thus, longitudinal SST gradients, areas of active upwelling or divergence and areas of sharp thermal gradients would not be expected to be well represented in the model SSTs.

To identify these areas of expected SST mismatch, we compared both Control $P$ (330ppm CO2) and Control Pi (280ppm CO2) SSTs for August and February to the GOSTA climatology (a 30 year average at 1 degree grids). To calculate differences between the GOSTA and model results, we used the model grid center and calculated the nearest GOSTA SST. This the point by point comparison approach may induce some mismatch since the model SST represents a larger area, but this seems to be a minor consideration.

We found that the largest SST differences between observed and model were not the dynamical areas and longitudinal gradients, but were often at high latitudes . In general, we find that:

1. The high latitudes (especially the southern hemisphere) is too warm and the tropics are too cold. The SSTs in the Southern Hemisphere is systematically much too warm. This is not associated with the sea ice edge (a problem that still needs to be sorted out in the comparison of these two climatologies). Regional anomaly patterns due to limited dynamics in the CCM-1 ocean are superposed on this larger scale pattern.

2. Meridianal transects through the Atlantic, Pacific, and Indian Oceans show significant variability. These results indicate that the single annual average $Q$-flux approach is not tuned well enough to compute SSTs that are compatible with observed SST.

3. The current Q-flux adjustment doesn't seem to be able to capture the subtropical convergence gradients. In part because this feature is not strictly zonal and also changes position seasonally. Given the high SSTs at $60^{\circ} \mathrm{S}$, it is difficult to understand how CCM-1 can computethe correct location of the sea ice boundary in the southern hemisphere.

Our major finding is that problems with the Q-flux could be part of difference between CLIMAP SSTs in the tropics and model computed SSTs which tend to be colder than CLIMAP in the tropics. In general, the CCM1 computed SSTs are too cold in the tropics and too warm in the high latitudes (ewspecially ijn the southern Hemisphere). In summary, we have identified some significant problems with the methodology for tuning the oceanic heat transport in CCM-1. We will pursue either a new (probably spatial) Qflux runing or ggo to a model that contains a better oceanic heat transport for the comparison of paleo SST experiments.

\section{PMIP EXPERIMENTS}

\section{PMIP Experiments}

Our 6000 yr BP and 21,000 yr BP experiments with CCM1 are being analyzed as part of PMIP. We continue to work closely with PMIP to coordinate this work. The coleaders of PMIP, Sylvie Joussaume and Karl Taylor, attended our COHMAP meeting this past June. We worked with them to encourage PMIP participants to consider using a "pre-industrial" control simulation $\left(\mathrm{CO}_{2}\right.$ level $\left.=280 \mathrm{ppmv}\right)$ rather than a modern control $\left(\mathrm{CO}_{2}\right.$ level - 340-350 ppmv). The pre industrial simulation provides a better baseline for comparison with "present-day" observations from ocean sediments and lake sediments (see below). 
- Carbon dioxide levels

During the past year, a major question arose concerning the appropriate $\mathrm{CO}_{2}$ level for the modern control experiments for the PMIP comparisons. We made a strong case that the PMIP proposed 345ppm was too high and would not be compatible with the ocean control SST and especially not compatible withj the marine sediment (core top) proxies for SST, which may represent several 100 years of climate history. This discussion resulted in the decisiion to develop a Prelndustrial Control $(\mathrm{Pi})$ that contains $280 \mathrm{ppm} \mathrm{CO} 2$. The $65 \mathrm{ppm}$ difference gives significantly lower ocean SSTs and is much more appropriate for comparisons between computed SST (both model and proxy) and observed SST.

\section{Model/Model Comparisons}

We are completing an experiment with CCM1 for 125,000 yr BP orbital conditions that will be used by Sylvie Joussaume and colleagues for a model-model intercomparison with the results of the French Climate Model for the same period. Other model/model comparisons will be made as a central part of the PMIP plan.

\section{SENSITIVITY EXPERIMENTS AND FEEDBACK STUDIES}

\section{A. Model Sensitivity Studies}

We focused our sensitivity studies this past year on the topics outlined in the full proposal. We continue to use CCM1 for the bulk of our simulations, although some work has been done with CM2 and GENESIS. We compared the CCM1 sensitivity to changes in $\mathrm{CO} 2$ to changes in te solar constant, and evaluated the basic model sensitivity to orbital insolation changes and to increases iatmospheric sulfate. We continued our examination of the sensitivity of climate to ice sheet configurations, as well as the reverse case of sensitivity of $i$ ce sheet configuration on climate. In an important new study, we investigated the CCM1 response to a preindustrial $(265 \mathrm{ppm})$ level of $\mathrm{CO} 2$, which had strong implications for the new set of model time slice simulations.

\section{1) Sensitivity of Climate to external forcings}

Marshall et al. (1994) compared the sensitivity of the CCM1 to changes in solar luminosity (solar constant) with the sensitivity to $\mathrm{CO} 2$ obtained by Oglesby and Saltzman (1992). Many similarities were found between these sensitivities, despite the very different spatial and temporal nature of the two forcings. The response in both cases is dominated by nonlinear feedbacks that appear to operate in roughly the same manner. This supports the basic premise of our research, namely, the idea that validation of GCMs through their capabilities at simulating past climates is a good guide to their power at predicting future climatic changes.

In a closely related study, Felzer et al. (1995) evaluated the sensitivity of CCM0 to orbital insolation changes, computing geographic sensitivity coefficients that were normalized to the insolation change involved. Since orbital insolation changes are a primary external forcing agent in late Pleistocene climate, this work is an important link with the $\mathrm{CO} 2$ and solar constant sensitivity studies.

In another related study, Erickson, Oglesby and Marshall (submitted) considered the sensitivity of CCM1 to the indirect effects of atmospheric sulfates (which act to increase cloud albedos). Signficant responses were found, especially in winter. Of particular interest, the nature, or patterns, of response was quite similar to those obtained in the comparative CO2-solar constant study. 


\section{2) Sensitivity to Ice Sheets}

During 1994, Ben Felzer, a Ph. D. candidate at Brown, completed experiments with CCM1 that show that the full impact of cooling and weakened monsoons for the last glacial maximum (LGM) is a factor of the northern hemisphere ice sheet albedos alone, and that the dynamical response in the vicinity of the ice sheets and downstream from them is dependent upon the ice sheet height. He presented these results in a talk (and abstract) at the American Meteorology Society (Felzer et al., 1994) meeting in Nashville, TN (Jan. 24-28, 1994), and in a poster (and abstract) at the American Quaternary Association (Felzer et al., 1994) conference in Minneapolis, Mn. (June 20-22, 1994). He also expanded his project to include the new ICE-3G ice sheets digitized by R. Peltier. Comparisons with the new COHMAP baseline simulations show that at the LGM the effects of the ice sheets and $\mathrm{CO}_{2}$ are comparable in CCM1, and account for most of the simulated cooling. Felzer presented these results in a talk at the COHMAP conference in Madison, Wi. (June 24-28, 1994). He are currently in the process of preparing two papers for publication covering these results, which will be part of his Ph.D. thesis.

Felzer made a systematic analysis of the sensitivity of CCM1 to changes in the height and area of northern hemisphere ice sheets. Primary goals of this research were (i) to distinguish the thermodynamic and dynamic effects of an ice sheet as partitioned in the ice sheet height and area and (ii) to analyze the nature of the local, regional, and far-field climatic responses.

Three sets of ice sheet boundary conditions were used in his study: (1) an LGM ice sheet; (2) a flat ice sheet with the LGM ice sheet area; and (3) a modern control. The area of the LGM and flat ice sheets was based upon the Denton and Hughes maximum reconstruction of the LGM (Denton and Hughes, 1981), and the height was uniformly set equal to $2500 \mathrm{~m}$ for the LGM run and $0 \mathrm{~m}$ for the flat ice sheet run. Except for the ice sheets, all of these model runs involved modern boundary conditions and forcings (including a $\mathrm{CO}_{2}$ value of $330 \mathrm{ppm}$ ). He had previously run one set of these three experiments using modern, fixed sea surface temperatures (SSTs), and this year completed another set using SSTs computed with a slab ocean. He also ran a fourth experiment of the LGM ice sheet with fixed CLIMAP (1981) SSTs, to finalize conclusions about the fixed SST response.

Felzer's results show that when fixed modern SSTs are used, the climatic sensitivity to ice sheet changes is limited to local and regional responses, and the resulting global mean temperature (GMT) changes are less than $1^{\circ} \mathrm{C}$ colder from the modern control. The computed SST experiments show limited far-field responses, but local responses that are larger than in the fixed SST cases. The flat ice sheet itself shows a $3^{\circ} \mathrm{C}$ GMT cooling from the modern control, with enhanced cooling in Asia, and a resulting weakening in the Asian monsoon. Therefore the effect of northern hemisphere ice sheets on the monsoon is primarily a thermodynamic effect. The ice sheet height is an important factor affecting the local and regional response, but has only a secondary impact on the far field response. The primary local responses of the high ice sheet, relative to the modern control and the flat ice sheet, are colder surface temperatures over the ice sheets and the development of glacial anticylones. The regional responses of the high ice sheet differ from the flat ice sheet and modern conditions because of the dynamic effect of the ice sheet on the upper atmospheric circulation, resulting in increased waviness and an enhanced mid-latitude jet stream. This increased waviness actually acts to limit the degree of cooling across Asia, with the subsequent weakening of the monsoon.

Felzer also examined the role of northern hemisphere ice sheets on the climate since the LGM. This research is directly linked to the latest set of COHMAP baseline 
simulations for $21 \mathrm{ka}$ to present using Peltier's (1991) ICE-3G reconstructions of the ice sheets. Primary goals of this research were (i) to distinguish the climatic response of the ice sheets from the response of other boundary conditions such as $\mathrm{CO}_{2}$, solar insolation, and ocean heat transport used by COHMAP, and (ii) to compare the sensitivity of these other boundary conditions to that of the ice sheets.

Five sets of ice sheet boundary conditions were used in this study, all based upon the ICE-3G ice sheet reconstructions (Peltier, 1991): 21, 16, 14, $11 \mathrm{ka}$, and a modern control (similar to the one used above). Except for the ice sheets, all of these model runs involved modern boundary conditions and forcings (including a $\mathrm{CO}_{2}$ value of $330 \mathrm{ppm}$ ), and SSTs computed with a slab ocean. Felzer compared his results with the new COHMAP baseline simulations for each of these time periods, and with other generic sensitivity experiments, such as the Oglesby and Saltzman (1992) $\mathrm{CO}_{2}$ sensitivity work.

Comparison of his $21 \mathrm{ka}$ sensitivity run with the COHMAP $21 \mathrm{ka}$ simulation reveals the extent of differentiation between ice sheet and $\mathrm{CO}_{2}$ responses. GMTs (boreal winter) are $2.7^{\circ} \mathrm{C}$ colder than the control for the $21 \mathrm{ka}$ ice sheet, and $6.3^{\circ} \mathrm{C}$ colder than the control for the COHMAP $21 \mathrm{ka}$ simulation (where the $\mathrm{CO}_{2}$ concentration has decreased by $76 \mathrm{ppm}$ from the control to $21 \mathrm{ka}$ ). The temperature decrease expected from a $76 \mathrm{ppm}$ $\mathrm{CO}_{2}$ decrease is equal to $2.2^{\circ} \mathrm{C}$, which accounts for all but $1.4^{\circ} \mathrm{C}$ of the difference between the sensitivity and simulation results $\left(3.6^{\circ} \mathrm{C}\right)$. The response to the ice sheets at the LGM is similar in magnitude to the response of the decreased $\mathrm{CO}_{2}$. Furthermore, the residual temperature responses without the ice sheet effects show similar patterns to the $\mathrm{CO}_{2}$ sensitivity patterns calculated by Oglesby and Saltzman (1992). To the first order, therefore, the responses of ice sheets and $\mathrm{CO}_{2}$ add together linearly within CCM1. The remaining $1.4^{\circ} \mathrm{C}$ of difference can be attributed to error $\left(0.5^{\circ} \mathrm{C}\right), 21 \mathrm{ka}$ solar insolation, and non-linear cross terms between ice sheets and $\mathrm{CO}_{2}$. Comparisons of his $11 \mathrm{ka}$ sensitivity run with the COHMAP $11 \mathrm{ka}$ simulation reveals the extent of differentiation between ice sheet and solar insolation responses. This comparison shows that the GMT (difference with control) attributable to the $11 \mathrm{ka}$ ice sheets is similar in magnitude to that attributable to the $11 \mathrm{ka}$ solar insolation effects.

\section{3) Sensitivity of Northern Hemisphere Ice Sheets to Changes in $\mathrm{CO} 2$}

Verbitsky (Yale) and Oglesby have previously completed a study of the sensitivity of northern hemisphere ice sheets to changes in atmospheric $\mathrm{CO} 2$ (Verbitsky and Oglesby 1992). Verbitsky and Oglesby (submitted) expanded this study to evaluate the effects of a doubling of $\mathrm{CO} 2$ on the Greenland and Antarctic ice sheets, tuning the ice sheet model to the GCM present-day control simulation such that the present-day Greenland and Antarctic ice sheets were correctly simulated. The GCM-simulated change in snow accumulation when $\mathrm{CO} 2$ was doubled was then used to compute the change in the ice sheets. Most of both ice sheets showed a decrease in volume, but both showed some regions where volume increased (because of increased snowfall with $2 \mathrm{XCO} 2$ ). No indication was found of rapid changes that have been speculated to occur in the West Antarctic ice sheets.

\section{4) Response of CCM1 to Preindustrial Levels of $\mathrm{CO} 2$}

Marshall et al. (1994) examined the response of the CCM1 to a pre-industrial level of 265 ppm CO2, comparing this response both to the model control (with $330 \mathrm{ppm}$ ) and to changes in the observed climate over the last 100 years. Changes between 330 and 265 ppm were largest in winter, with changes in sea ice playing a major role. Continental temperature changes show a fair degree of correspondence with the changes (generally increases) observed over the last 100 years. Besides its obvious importance in assessing 
the role of $\mathrm{CO} 2$ in recent climatic changes, this work assumed new importance with the realization that the new COHMAP 'control' simulation required a preindustrial value of $\mathrm{CO} 2$, as opposed to a 'modern' (ie., $330 \mathrm{ppm}$ ) value.

\section{B. Model Development}

Our sensitivity and paleoclimate studies have pointed out the importance of a correct simulation of sea ice and of snow cover. We have continued our work towards developing better paramterizations for these quantities.

\section{1) Coupling an ocean mixed-layer and sea ice model to CCM1}

Work has progressed on the coupling of the Martinson mixed-layer and sea ice model into CCM1 and then into CCM2. This task has proven more difficult and tedious than we originally anticipated, however, virtually all of our modeling work points to the importance of accurate determinations of sea ice and sea surface temperature. Monica Stephens, a Ph.D. student in Applied Math at Brown, has taken on this task as a primary component of her dissertation research, working closely with Marshall, Oglesby, and Webb.

\section{2) Improved Snow Hydrology in CCM1}

As described in the proposal, Marshall (UNCC) and Oglesby have successfully implemented the sophisticated snow albedo and hydrology scheme of Marshall (1989) into CCM1. The paper reporting on this work is now in print (Marshall and Oglesby 1994). Further work is currently underway to add additional features to the snow scheme, and to couple the snow scheme to CCM2 and to the Bio-Atmsopheres Transfer Scheme (BATS), which is an option in CCM2 (and also then allows for use in the regional climate model RegCM).

\section{Other Project Work}

\section{1) Holcene High Plains Aridity}

This new study, not anticpiated in previous proposals, but clearly relevant to our overall goals, involved an investigation of the climatic patterns responsible for alternating periods of drought and relatively wet conditions over the US during the Holocene (Forman et al 1994). The record was based on analyses of presently stabalized dunes from eastern Colorado and Nebraska. The climate scenarios were based on current observations and on GCM studies. Of key importance is moisture flow from the Gulf of Mexico. When mean synoptic patterns in late spring and summer are conducive to flow of this moist air into the central US, then vegetation grows and the dunes become stabilized. When the mean synoptic patterns are not conducive to this flow of moist air, then the vegetation dies off and the dunes become activated. This work will ultimately allow us to do model-data comparisons in a region for which we have relatively little other geologic data (e.g., from pollen).

\section{2) Model Hydrology and Snowcover}

Fan (1993 Master's thesis) and Fan and Oglesby (submitted) evaluated the effects of climatic variability on the hydrologic cycle of eastern North America and North China. This work used many of the same analysis techniques as Clemens and Oglesby (1992) and can be considered an extension of that study. The analysis was based on a 100 year CCM1 simulation, and demonstrated that drought periods could be induced solely as a result of natural variability. Kleidon and Oglesby (submitted) provided a detailed examination of the response of precipitation in CCM1 as a function of CO2. They found that the number of events per unit time changed very little, but that the precipitation rate 
per event increased as CO2 increased. Dismukes (in progress) has provided a detailed look at stormtracks in the northern hemisphere in CCM2, which will provide important background as we shift towrds this new model.

\section{3) Sensitivity to prescribed vegetation type}

We completed a study of the potential feedbacks of vegetation on climate at 6000 yr BP. The results were recently published in Nature (Foley et al., 1994). This paper shows that orbital forcing alone could have raised high latitude temperatures by about $2{ }^{\circ} \mathrm{C}$, and that the northward spread of boreal forest (in response to the orbital warming), replacing tundra, could have raised temperatures another $2^{\circ} \mathrm{C}$. The total simulated warming of about $4^{\circ} \mathrm{C}$ is in the correct ball park with the limited paleoclimatic observations from the Arctic, especially the Eurasian Arctic. The potential for biosphereclimate feedback appears to be large in the far north and we are continuing these studies.

\section{4) Sensitivity to orbital extremes}

A paper showing simulated biome changes for extreme warm summer orbits (similar to conditions at $125,000 \mathrm{yr} \mathrm{BP}$ ) and extreme cold summer orbits (similar to conditions at 115,000 yr BP) is in press in Quaternary Research (Harrison, et al., 1994). We have also completed an assessment of the sensitivity of snow cover and sea ice cover to orbital extremes. The paper is in press in JGR (Gallimore and Kutzbach, 1994).

\section{HIGH RESOLUTION CLIMATE MODEL RUNS USING THE PURDUE-IBM FACILITY}

The Purdue Climate Modeling Facility described in the Full Proposal is now fully on-line. This facility consists of a 9 processor IBM SP2, as well as about a dozen highpowered workstations. We have CCM2, MM4, and the Purdue Mesoscale Model (PMM) now running on the system, with final testing just about completed. Thus, during the next year of our project we expect to begin making use of this facility for our DOE project.

\section{DATA-MODEL COMPARISON USING LONG PALEO- CLIMATIC TIME SERIES}

No research was completed on this task during 1994. Our major effort will be during the third year of this grant.

\section{DATA BASE DEVELOPMENT}

\section{A. Terrestrial Data}

One of us (TW) co-organized a workshop in Lund Sweden in May, 1994 under the sponsorship of the GAIM Task Force and other IGBP projects. The workshop formally initiated a world wide collaborative project to develop a global paleovegetation data set for $6 \mathrm{ka}$ and $21 \mathrm{ka}$ as well as other dates of potential interest. Each continent was represented by a good cross section of research leaders in paleoecology. Active researchers from the tropics and semi-arid regions participated and will contribute date from these relatively under-represented areas. The project will give priority to $6 \mathrm{ka}$ and $21 \mathrm{ka}$ to help with the data/model comparisons for PMIP and a major project in GAIM.

Maps of the sites with available data were prepared for and distributed at the meeting. Their preparation was a major task at Brown in early 1994. As part of this task, much of the data at Brown were transferred to Paradox for data management. At the workshop, T. Webb was selected as the global data coordinator for the project and will 
serve on the Steering Committee. $T$. Webb is also coordinating the group of 8 paleoecologists organizing the data for North America. The meeting and project plans are described in Prentice and Webb (1994).

This coodinated project represents a major step forward for developing global data sets for data/model comparison. For the first time, original data will be made available from tropical and other under-represented regions of the globe. The initiation of the project was a key accomplishment for 1994 and its completion over 1995 and 1996 will be key achievements for this grant period.

\section{B. Marine Data}

The major marine-based data required for comparisons to the COHMAP baseline series and PMIP are core-top control data, additional data for the LGM, and time series data from selected oceanographic sites. During the past year, we have continued to focus on the re-evaluation, documentation, and expansion of the core-top planktonic foraminfera calibration database (under DOE and NSF/NOAA funding). We have evaluated all data in our previous global database (Prell, 1985) and have eliminated estimates which could not be documented by a curated sample. We have completely reanalysed, documented, and included in the data base almost 800 samples, primarily from the Atlantic and Indian Oceans. In addition, as part of our effort to insure that all core tops are of recent age, we have measured the oxygen and carbon isotopic composition of about 200 Indian Ocean and 120 Pacific Ocean samples. The comparison of the isotopic composition along with the faunal composition and preservation state will help us identify any samples that are not compatible with the modern surface sedimentrs.

- Core-Top SSTs

The differences between observed (GOSTA) SSTs and SST estimates from core top plankton assemblages will identify any biases or inability of the paleo-SST equations and samples to reconstruct the modern calibration data. Any systematic differences could bias the interpretation of paleo $\triangle S S T$ estimates and has been suggested as a possible source of disagreement between CLIMAP and model SST estimates. Also the choice of calculating the paleo $\triangle$ SST from observed climate data (GOSTA) or core-top SST data is important. The latter comparison is similar to comparing model experiments to the model control case in that any biases relative to observed data are removed and only relative departures are analyzed.

We have compared the core top SST estimate with the GOSTA control SST for over 150 cores that also have LGM SST estimates. We find no systematic biase between the core top SST estimates and the GOSTA control SSTs. The departures were normally distributed and had an average (absolute value) of about $0.50 \mathrm{C}$. Further we found no systematic patterns within individual oceans.

These initial tests indicate that the use of observed climatology or core top EES estimates as the basis for calculating past SST departures from modern ocean is not a significant problem and is not likely the cause of the differences between CLIMAP and model results. 


\section{References}

Clemens S. C. and R. J. Oglesby (1992). The role of interhemispheric moisture transport in the Indian Ocean Summer monsoon: Data-model and model-model comparisons. Paleoceanography, 7, 633-643.

CLIMAP (1981). Seasonal reconstructions of the Earth's surface at the Last Glacial Maximum. Geological Society of America Map Chart Series MC-36.

Denton, G. H. and T. J. Hughes (1981). The Last Great Ice Sheets. New York, John Wiley and Sons.

Felzer, B., R. Oglesby, D. Hyman and T. Webb III (1994). Sensitivity of the global climate system to changes in northern hemisphere ice sheet size using the NCAR CCM1. 6th Conference on Climate Variations, Nashville, TN., American Meteorological Society.

Felzer, B., R. Oglesby, D. Hyman and T. Webb III (1994). Sensitivity of the global climate system to changes in northern hemisphere ice sheet size using the NCAR CCM1. American Quaternary Association, Minneapolis, MN., American Quaternary Association.

Felzer B., R. J. Oglesby, H. Shao, T. Webb III, D. Hyman, W. L. Prell, and J. E. Kutzbach (1995). A systematic study of GCM sensitivity to changes in solar radiation. J. Climate, in press.

Foley, J.A., J.E. Kutzbach, M.T. Coe, and S. Levis (1994). Feedbacks between climate and boreal forests during the Holocene epoch. Nature 371, 52-54.

Forman, S.L., R.J. Oglesby, V. Markgraf, and T. Stafford Paleoclimatic significance of Late Pleistocene eolian deposition on the piedmont of eastern Coloradao. Global and Planetary Change, in press.

Gallimore, R.G. and J.E. Kutzbach (1994). Snowcover and sea ice sensitivity to generic changes in earth orbital parameters. Journal of Geophysical Research-Atmospheres (in press).

Harrison, S.P, J.E. Kutzbach, I.C. Prentice, P.J. Behling, and M.T. Sykes (1994). The response of northern hemisphere extratropical climate and vegetation to orbitallyinduced changes in insolation during the last interglacial. Quaternary Research (in press).

Kutzbach, J.E. and P.J. Behling (1994). Comparison of paleoclimate simulations and observations. Newsletter: INQUA-Commission for the Study of the Holocene, Working Group on Data-Handling Methods Newsletter, July 94. Louis J. Maher, Jr. (ed).

Kutzbach, J. E., P. J. Guetter, P. J. Behling and R. Selin (1993). Simulated climatic changes: results of the COHMAP climate-model experiments. Global Climates since the Last Glacial Maximum. University of Minnesota Press. 24.

Marshall, S. and Oglesby, R. J., 1994, An improved snow hydrology for GCM's Part 1: Snow cover fraction, albedo, grain size, and age. Climate Dynamics, 10, 21-37. 
Marshall, S., R. J. Oglesby, J. W. Larson, and B. Saltzman (1994). A comparison of GCM sensitivity to changes in $\mathrm{CO} 2$ and solar luminosity Geophys. Res. Letters, in press.

Marshall, S., M. E. Mann, R. J. Oglesby, and B. Salztman (1994). A comparsion of the CCM1-simulated climates for pre-industrial and present-day $\mathrm{CO} 2$ levels. Global and Planetary Change, in press.

Oglesby, R. J. and B. Saltzman (1992). Equilibrium climate statistics of a GCM as a function of atmospheric CO2: II. Implications for paleoclimates. Journal of Climate, 5, 66-92.

Peltier, W. R. (1991). The ICE-3G model of late Pleistocene deglaciation: construction, verification, and applications. Glacial isostacy, sea-level and mantle rheology. The Netherlands, Kluwer Academic Publishers. 95.

Prentice, I. C. and T Webb III (1994). BIOME 6000: Towards a global palaeovegetation data set. IGBP Newletter, 19, 8-9.

Verbitsky, M. Ya and R. J. Oglesby (1992). The effect of atmospheric carbon dioxide concentration on continental glaciation of the northern hemisphere. Journal of Geophysical Research, 97, 5895-5909.

Webb, T. III, P.J. Bartlein, S.P. Harrison, and K.A. Anderson (1993). Vegetation, lakelevels, and climate in eastern United States. p. 415-467. In Global Climates since the Last Glacial Maximum (H.E. Wright, Jr., Jr., J.E. Kutzbach, T. Webb III, W.F. Ruddiman, F.A. Street-Perrott, and P.J. Bartlein, eds.), University of Minnesota Press, Minneapolis.

Wright, H.E., Jr. J.E. Kutzbach, T. Webb III, W.F. Ruddiman, F.A. Street-Perrott, and P.J. Bartlein (1993). Global Climates Since the Last Glacial Maximum. University of Minnesota Press, $544 \mathrm{pp}$.

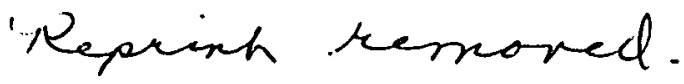

